\title{
Perspectiva constitucional colombiana de la Comunidad Andina: la jurisprudencia constitucional del Acuerdo de Cartagena*
}

\author{
Colombian constitutional perspective of \\ the Andean Community: the constitutional \\ jurisprudence of the Cartagena Agreement
}

Fecha de recepción: 14 de abril de 2011 Fecha de evaluación: 14 de junio de 2011 Fecha de aprobación: 21 de junio de 2011

Jorge Ricardo Palomares G. LL.M.**

\section{Resumen}

El presente escrito busca describir el entendimiento de la jurisprudencia constitucional del proceso de integración andino. Para ello, se revisarán los fallos de la Corte Constitucional, a fin de determinar los criterios constitucionales que permanecen vigentes desde 1968 con la Corte Suprema de Justicia y cuáles han sido los nuevos criterios aportados por la Corte Constitucional.

Palabras clave: Integración regional, Comunidad Andina, Constitución de 1886, Constitución de 1991, jurisprudencia constitucional

\footnotetext{
Abstract

This paper seeks to describe the understanding of the Constitutional jurisprudence of the Andean integration process. To this purpose, we review the rulings of the Constitutional Court, to determine the constitutional criteria that have remained in force since 1968 with the Supreme Court and what have been the new criteria of the Constitutional Court.

Keywords: Regional Integration, Andean Community, Constitution of 1886, Constitution of 1991, Constitutional Decisions

* Artículo de reflexión.

** Abogado de la Universidad Santo Tomás, Bogotá; Legum Magister de la Universidad Konstanz, Alemania; Docente tutor de la Maestría en Derecho Público de la Universidad Santo Tomás; Docente de la cátedra Argumentación jurídica de la Facultad de Derecho de la Universidad Santo Tomás; Investigador del proyecto "Globalización del Derecho de los Contratos" U. Santo Tomás-GIZ.
} 


\section{INTRODUCCIÓN}

La Comunidad Andina (en adelante CAN) ha sido un bloque regional caracterizado por una experiencia dual. Por una parte, es uno de los procesos de integración latinoamericanos con una estructura jurídica institucional y normativa avanzada. Por otro lado, las relaciones comerciales y políticas de la CAN han contado con diferentes problemas que no permiten su progreso, tales como la aplicación del sistema de sustitución de importación en la década de los setenta y mitad de los ochenta, las complicaciones en las relaciones entre Colombia y Venezuela, la celebración independiente de tratados de libre comercio, entre otros. Esto se ha discutido en diferentes estudios que tienden a calificar la situación de la CAN como un estado crónico, caracterizado por problemas de la eficacia del derecho comunitario (Arroyave, 2008), los conflictos colombo-venezolanos (Milanese, 2005), entre otros.

Sin embargo, el presente escrito no pretende analizar la situación institucional y jurídica de la CAN, sino un elemento esencial para la existencia de un proceso de integración regional: la legitimación constitucional. Los bloques regionales no pueden existir o funcionar si no existen normas constitucionales que le permitan al Estado ceder competencias para constituir escenarios de libre funcionamiento del mercado y crear instituciones regionales competentes para producir normas que diseñen, regulen y faciliten la consolidación de dicho escenario. El análisis de la existencia de una norma constitucional legitimadora del bloque regional se encuentra no sólo con la consagración de una norma en la Constitución, sino con el estudio realizado por la jurisdicción constitucional, la cual se encarga de determinar el contenido y límites, desde la perspectiva constitucional, de un proceso de integración. Por tanto, el escrito, en marco de los veinte años de la Constitución Política de 1991, abordará la perspectiva constitucional de la Comunidad Andina, a través del desarrollo jurisprudencial de la Corte Constitucional. Para ello, se explicarán los criterios jurisprudenciales que permitieron la entrada en vigor del Acuerdo de Cartagena en el Estado colombiano, elaborados por la Corte Suprema de Justicia en virtud de la Constitución de 1886 (II). Posteriormente, se revisarán los criterios asumidos por la Corte Constitucional, en virtud de la Constitución Política de 1991 (II), a fin de establecer cuáles son comunes entre esta y la de 1886, cuáles han cambiado o han sido incorporados por la Corte Constitucional y cuál es el estado actual de la CAN bajo la interpretación de trato preferencial de la integración latinoamericana.

\section{VIGENCIA DE LA COMUNIDAD ANDINA (PACTO ANDINO) EN LA CONSTITUCIÓN DE 1886}

\section{A. Precisiones normativas de la Constitución de 1886}

La Constitución de 1886 no contaba, a diferencia de la de 1991, con un sistema normativo avanzado o apto para la participación de Colombia en un proceso de integración. Básicamente, la Carta de 1886 contaba con reglas básicas de división de competencias ${ }^{1}$ que permitían la celebración de tratados internacionales. Su artículo 120, numeral 10, establecía que el Presidente de la República, como suprema autoridad administrativa, era competente para la dirección de las relaciones diplomáticas y comerciales con las demás potencias o soberanos y para la celebración de tratados y convenios con los mismos; el artículo 76, numeral 20, facultaba al Congreso de la República para aprobar o desaprobar los tratados que el gobierno celebrara con potencias extranjeras. Mientras que la Corte Suprema de Justicia (en adelante CSJ) no

1 Ejemplo del diseño constitucional respecto a tratados internacionales es el análisis realizado por Pérez E. (1974: 389 y ss.), para quien las relaciones internacionales deben verse desde las competencias del Congreso y de la Administración, quienes participan en etapas concretas de la formación de tratados internacionales, es decir, en la negociación, la ratificación y la firma de los mismos. 
gozaba de competencia para la revisión de tratados internacionales. En este sentido, pareciese que no existiera en el ordenamiento jurídico colombiano una norma que legitimase la conformación de un bloque regional, al cual se le pudiese conferir competencias.

A fin de evitar una posible incompatibilidad con la Constitución en el momento de celebrar el Acuerdo de Cartagena, se reformó el artículo 76 de la Constitución de 1886, mediante Acto Legislativo 1 del 11 de diciembre de $1968^{2}$. Dicha reforma cambió el artículo 20 por el 18 de la Constitución de 1886, estableciendo que corresponde al Congreso aprobar o improbar tratados o convenios que el gobierno celebre con otros Estados o con entidades de derecho público internacional. Por medio de tratados o convenios aprobados por el Congreso -continúa la norma- podrá el Estado obligarse para que, sobre bases de igualdad y reciprocidad, sean creadas instituciones supranacionales que tengan por objeto promover o consolidar la integración económica con otros Estados. Mediante esta reforma, se trató de incluir varios conceptos que permitiesen un comportamiento armónico entre el ordenamiento jurídico colombiano y el próximo ordenamiento jurídico comunitario. Por una parte, se reconoce la participación del Estado colombiano en procesos de integración regional, que tengan como finalidad el cumplimiento de metas económicas. Dicha integración puede contar, por otra parte, con instituciones supranacionales, con capacidad de proferir normas independientes a las proferidas por el Congreso.

2 La Reforma de 1968, liderada por Carlos Lleras Restrepo, tuvo como objetivos esenciales, según Henao (1976: 61 y ss.), la modernización del Estado, la redistribución de las funciones entre las ramas Ejecutiva y Legislativa, la tecnificación del Congreso y actualizar el régimen administrativo de los departamentos y municipios. Dichos objetivos se consagraron (Restrepo P., 1995: 517 y ss.) en el Acto Legislativo 1 de diciembre de 1968, el cual cuenta con 77 artículos.

\section{B. Jurisprudencia de la Corte Suprema de Justicia}

La CSJ se manifestó en tres ocasiones sobre las relaciones entre la Comunidad Andina (antes Pacto Andino, en adelante CAN) y el ordenamiento jurídico colombiano, de las cuales sostuvo dos posturas: a) la no existencia de un derecho comunitario y b) la existencia de un derecho comunitario con efectos propios. La primera se desarrolló a través de las sentencias CSJ, Sala Plena, del 26 de julio de 1971, m. p. José Gabriel de la Vega, y CSJ, Sala Plena, del 20 de enero de 1972, m. p. José Gabriel de la Vega; la segunda postura se expuso en Sentencia CS], Sala Plena, del 27 de febrero de 1975, m. p. José Gabriel de la Vega.

\section{Negación del derecho comunitario}

La primera postura de la CSJ-Sala Plena se sostuvo a través de tres argumentos ${ }^{3}$ : a) la aplicación de la teoría de Tratado Marco (Botero M., 1972: 112; Gómez L., 1977: 78); b) competencias constitucionales en las relaciones internacionales, y c) la existencia de un acto administrativo complejo ${ }^{4}$.

La CSJ-Sala Plena analiza la teoría del Tratado Marco teniendo en cuenta que el Ejecutivo, al expedir el Decreto 1245 de 1969, tuvo como considerandos especiales el artículo 2o de la Ley 88 de 1961 (por el cual se ratifica el ALALC, Tratado de Montevideo, en adelante TM) y la Resolución 179 de 1969, que considera el Acuerdo de Cartagena compatible con el TM. La pregunta central de la CSJ-Sala Plena fue si era entender el Acuerdo de Integración Subre-

3 Botero M. (1972), quien realiza una reflexión sobre las sentencias de la CSJ, establece como cadena argumentativa para la determinación de la constitucionalidad de los decretos 1245 de 1969 y 1299 de 1971: a) la violación inequívoca de la Constitución; b) la competencia de la CSJ, y c) la falta de jurisdicción.

4 La teoría del acto complejo, de acuerdo con Saldarriaga (1984: 99 y ss.) y con el criterio de la CSJ desde 1914, es aplicable a las leyes aprobatorias de tratados, las cuales, pese a ser una competencia del Congreso, incorporan normas que el mismo no puede modificar, pues constituyen acuerdos celebrados por Estados, que escapan de la esfera interna del Estado. Sin embargo, la aplicación de esta teoría se amplía por la situación particular que se dio con el Acuerdo de Cartagena a los actos administrativos. 
gional como ejecución del TM -Tratado Marco- o si se hablaba de dos actos jurídicos independientes $^{5}$. Para ello, eran necesarios tres requisitos: a) la existencia de un tratado marco, en el cual se establecieran metas a mediano o largo plazos y de cláusulas que determinasen la forma en que dichas metas se alcanzarán mediante la elaboración de protocolos; b) identidad en cuanto a las partes contratantes y en cuanto a las materias objeto de regulación, y c) identidad de las instituciones reguladoras creadas por el Tratado Marco.

De acuerdo con el artículo $2^{\circ}$ del TM -art. $1^{\circ}$ de la Ley 88 de 1961-, la meta de la ALALC es el perfeccionamiento de la Zona de Libre Comercio (en adelante ZLC) en un término no mayor a doce (12) años. El artículo $3^{\circ}$ del TM consagra que el perfeccionamiento de esta ZLC implica la eliminación gradual de gravámenes y restricciones de todo orden que incidan sobre la importación de productos originarios del territorio de cualquier parte contratante. Por su parte, el artículo $1^{\circ}$ del Acuerdo de Cartagena (en adelante AC) establece que uno de los objetivos del instrumento es facilitar la participación de la Comunidad Andina (Pacto Andino) en el proceso de integración previsto en el TM y establecer las condiciones favorables para la conversión de la ALALC en un mercado común ${ }^{6}$. Pareciese -como lo sostuvo la CSJ-Sala Plena en sentencia del 26 de julio de 1971- que las normas

$5 \quad$ Esta cuestión es presentada por la CSJ-Sala Plena, mediante sentencia del 26 de Julio de 1971, como el enfrentamiento u oposición de dos tesis: "a) el Pacto Andino es un convenio internacional" $y$ "b) Ese acto no es sino un acuerdo complementario, un desarrollo del Tratado de Montevideo, inherente a su ejecución, sin identidad separada". Esta cuestión se abordó de forma similar por la CSJ-Sala Plena en sentencia del 20 de enero de 1972. Allí se cuestionó si bajo el término medidas, consagrado en el artículo $2^{\circ}$ de la Ley 88 de 1961, podían entenderse las decisiones No. 24 y 37 del Pacto Andino sobre el régimen común de tratamiento a los capitales extranjeros y sobre marcas, patentes, licencias y regalías del Acuerdo de Cartagena.

6 Esta disposición fue modificada por el Protocolo de Quito del 12 de mayo de 1987. El texto consagrado en el Protocolo elimina la mención expresa a la ALALC y su conversión en un mercado común por "[...] facilitar su participación en el proceso de integración regional, con miras a la formación gradual de un mercado común latinoamericano". del TM puedan entenderse como normas marco, pues sólo enuncian un programa y unas metas por realizar, que requieren de otros instrumentos para su plena ejecución; asimismo, pareciese que el artículo $1^{\circ}$ del AC no sólo manifiesta que la CAN busca la integración de los Estados parte, sino que también sirve como instrumento para la ejecución de los objetivos de la ALALC y para la transformación de la misma en un mercado común. Por tanto, el primer requisito se cumpliría, considerando que el TM y el AC buscan una integración de Estados latinoamericanos y, a su vez, este busca servir de complemento a aquel.

Sin embargo, del análisis de sendos instrumentos no es posible hablar de una identidad en cuanto a materias y partes contratantes. Por un lado, el artículo $3^{\circ}$ del Tratado de Montevideo establece como eje para la consolidación de la ZLC la libre importación de productos -comunes o agrícolas, regulados en los arts. 27 y ss. del TM- entre cada uno de los Estados miembros, mediante la eliminación de barreras, la formulación de listas -arts. $5^{\circ}$ y ss. del TM- y el tratamiento tributario igualitario -arts. 21 y ss. del TM-; el AC, a su vez, consagra en el artículo $3^{\circ}$ ocho metas u objetivos, de los cuales sólo el lit. c) busca una complementariedad explícita del TM para la consecución de los fines propuestos en la ALALC, mientras que el lit. d) formula implícitamente una medida para la transformación de la ALALC en un mercado común. Las demás materias consagradas en el AC no pueden verse como normas que busquen complementar o ejecutar el TM, sino como materias independientes e incluso más avanzadas o complejas que las propuestas en el TM, pues mientras este busca una armonización arancelaria y de tributos internos, el Acuerdo de Cartagena busca, además, el fortalecimiento de programas agrícolas, industriales, de inversión y de tratamientos preferenciales. En este sentido, no es posible hablar de un tratado marco, teniendo en cuenta que el AC no es un instrumento de ejecución, sino de la formulación propia de un proceso de integración independiente. 
Asimismo, es de anotar que los actores del ALALC no son los mismos que los de la CAN. EI TM tiene como Estados firmantes a Argentina, Brasil, Chile, México, Paraguay, Perú y Uruguay, y al que se adhiere posteriormente Colombia. El AC -incorporado por el Decreto 1245 de 1969- tiene como Estados contratantes a Bolivia, Colombia, Chile, Ecuador y Perú. Podría decirse que el AC constituye un instrumento para el fortalecimiento del ALALC ejecutado por Colombia, Chile y Perú. Sin embargo, es de anotar que en el AC surgen nuevos beneficiarios que no corresponden al ALALC, como Bolivia y Ecuador, mientras que no son partícipes o beneficiarios los Estados de Argentina, Brasil, México, Paraguay y Perú. Por tanto, y según el criterio de la CSJ-Sala Plena, no es sustentable la teoría de tratado marco, pues no existe una identidad entre los actores firmantes, entre los instrumentos internacionales, ni en cuanto a los beneficiarios.

Para poder hablar, por último, de la existencia de un tratado marco, es necesario que haya una identidad institucional entre el tratado inicial, en este caso el TM, y el segundo tratado o instrumento internacional, en este caso el AC. Los artículos 33 y ss. del TM establecen sólo dos instituciones para la ejecución de la ALALC: a) la Conferencia y b) el Comité Ejecutivo Permanente. La Conferencia, como órgano máximo de la ALALC, de acuerdo con el artículo 34 del TM, cumple con siete funciones, que se pueden resumir en determinar las acciones necesarias para la ejecución del tratado, la evaluación del progreso del mismo y la elección del Presidente de la ALALC; mientras que el Comité Ejecutivo Permanente, según el artículo 39 del TM, es el órgano encargado de velar por el cumplimiento del Tratado de Montevideo, mediante la ejecución de ocho funciones. Sin embargo, ni la Conferencia ni el Comité Ejecutivo Permanente son consagrados o reconocidos como órganos competentes de la CAN. El artículo $6^{\circ}$ del AC establece dos órganos del Pacto Andino: a) la Comisión y b) la Junta. La primera es el órgano máximo del Pacto Andino, cuenta con competencias más amplias que la
Conferencia de la ALALC, conforme a los artículos $7^{\circ}$ y $8^{\circ}$ del $\mathrm{AC}$, especialmente esta última norma, que faculta a la Comisión para promover la acción concretada entre los países de la integración subregional para afrontar problemas derivados del comercio internacional. La junta, por su parte, es el órgano técnico en términos del artículo $13 \mathrm{del}$ Acuerdo de Cartagena y su función es la de velar por el cumplimiento del AC y de la protección de los intereses de la sub-región, mediante la ejecución de diecisiete actividades consagradas en el artículo 15 del AC.

Pese a existir una identidad entre las metas propuestas por la ALALC y por el Pacto Andino, no se halla una identidad en cuanto a las materias concretas de regulación, los países firmantes ni en las instituciones reguladoras ${ }^{7}$. Por tanto, para la CSJ-Sala Plena no es posible hablar del TM como un tratado marco ni del AC como un instrumento de ejecución, sino de instrumentos internacionales independientes ${ }^{8}$.

La incidencia de no existir un tratado marco se proyecta en dos sentidos. Por una parte, para la CSJ-Sala Plena el proceso de integración andino es la constitución de una sub-región independiente y con dinámicas propias que no pueden entenderse en el marco de la ALALC. Por otra parte, y objeto central para la construcción del segundo argumento de la CSJ-Sala Plena, es el entendimiento

$7 \quad$ El ALALC y la CAN tampoco pueden entenderse como unidad pues, desde lo fáctico, la CAN nace como respuesta a los problemas surgidos de la ALALC (Barbosa M., 1972). El establecimiento de un libre flujo de productos a través de la eliminación de tributos a las importaciones no tuvo en cuenta las ventajas económicas que algunos de los países del ALALC tenían sobre otros -como el caso de Argentina, Brasil y México- (Armstrong, 1975). Ello implicó que Estados como Colombia, Perú y Ecuador buscasen un bloque con unas condiciones más equitativas para los demás países (Fuentes, 2007-08)

8 La CSJ-Sala Plena, en sentencia del 26 de julio de 1971, resume lo expuesto al afirmar que "las estipulaciones del Acuerdo de Cartagena, en cambio, ofrecen un campo de acción mucho más vasto que la mera negociación de reducciones aduaneras y otras restricciones en el movimiento de importaciones y exportaciones, abarcan diversos objetos de mayor substancia y dotan a la institución, para convertirlos en providencias actuantes, de medios de acción que ostentan notoria y rápida eficacia". 
de los actos de incorporación del AC -Decreto 1245 de 1969- y del régimen común de tratamiento a los capitales extranjeros y sobre marcas, patentes, licencias y regalías del Acuerdo de Cartagena -Decreto 1299 de 1971-.

Si el AC constituye un instrumento internacional de carácter independiente al TM, no es posible, en el entendimiento de la CSJ-Sala Plena, que el acto mediante el cual se incorpore se sustente en el TM, en el artículo $2^{\circ}$ de la Ley 88 de $1961^{\circ}$ o el artículo 15 del TM. Pero, más importante aún para la CSJ-Sala Plena, no es el fundamento en sí mismo, sino el tipo de acto por medio del cual los instrumentos se incorporan.

La teoría del tratado marco permitía que los actos que fuesen ejecución del TM se incorporasen sin necesidad de recurrir al sistema de ratificación de instrumentos internacionales. Ello se consagraba en el artículo $2^{\circ}$ de la Ley 88 de 1961, al establecer que el Gobierno Nacional está facultado para adoptar todas las medidas (...) que estime conducentes para la realización del Tratado [de Montevideo]. Dichas medidas se expresan a través de decretos 0 actos administrativos que el Gobierno Nacional esté facultado a proferir. Como el AC era entendido por el Ejecutivo como una medida de ejecución de la ALALC, consideró pertinente su inclusión mediante decreto. Pero, al considerarse el AC como un acto independiente que no corresponde a la aplicación del Tratado Marco, la CSJ-Sala Plena descarta de entrada la aplicación del artículo $2^{\circ}$ de la Ley 88 de 1961. Por tanto, la CSJ-Sala Plena se cuestiona si, desde el ámbito de competencias, el Ejecutivo está facultado para la expedición de decretos que incorporen instrumentos internacionales.

9 La CSI-Sala Plena concluye esto, en sentencia del 20 de enero de 1972, al afirmar que "[l]a cita del artículo 15 [del Tratado de Montevideo] carece, pues, de pertinencia; y por ello deja fuera de la Ley 88 [de 1961] al Decreto 1299 [de 1971], ya que este pretende ser el desarrollo de un convenio internacional a cuyas estipulaciones no se pliega".
Para la CSJ-Sala Plena, es claro que la competencia de ratificación de tratados o de instrumentos internacionales sólo es posible mediante la expedición de ley que, de acuerdo con el artículo 76, numeral 20, de la Constitución de 1886, es competencia exclusiva del Congreso y no es transferible al Ejecutivo, a quien sólo le es posible participar de la etapa de negociación y depósito de instrumentos internacionales. Aparentemente, la decisión de la CSJ-Sala Plena podría haberse detenido en declarar la inexequibilidad de los decretos 1245 de 1960 y 1299 de 1971 sin problema alguno, pues existe una violación manifiesta de las competencias constitucionales y del principio de separación de poderes consagrados en la Constitución de $1886^{10}$. Sin embargo, en el caso del Decreto 1245 de 1969, la CSJ-Sala Plena, en vez de proferir fallo de exequibilidad sobre el mismo, decide abstenerse argumentando la existencia de un acto complejo. Para la CSJ-Sala Plena, si bien existe una violación de competencias constitucionales, el Decreto 1245 de 1969 ya se encontraba en vigencia y constituía una norma compleja que, por una parte, ratificaba un instrumento internacional que, de acuerdo con la jurisprudencia de la misma corporación, no podía ser objeto de estudio y, al mismo tiempo, consagraba una actividad propia del Ejecutivo que podía ser objeto de decisión. En cuanto al aspecto de ratificación, la CSJ-Sala Plena afirmó que decidir la inexequibilidad del mismo sería atentar contra el sistema de derecho internacional, el cual se cimenta en el principio de buena fe $y($...) fallar en contra del decreto significaría que el AC no tendría vigencia en el territorio nacional e implicaría que el Estado colombiano negara la vigencia de un instrumento aceptado por los demás Estados firmantes y al mismo tiempo desacataría un deber de cumplimiento del mismo. Igualmente, no es posible, según el entendimiento de la CSJ-Sala Plena, argumentar culpa propia para no cumplir

10 Este es el argumento central de la CSJ-Sala Plena, en sentencia del 20 de enero de 1972, al declarar la inexequibilidad del Decreto 1299 de 1971. 
lo pactado, no es una alternativa viable para el Estado colombiano, quien se ciñe al principio de lealtad en el sistema internacional.

Desde estos tres argumentos, la CSJ-Sala Plena se orientó por la abstención sobre la exequibilidad del Decreto 1245 de 1969 y la inexequibilidad parcial del Decreto 1299 de 1971. Lo interesante del estudio de la CSJ-Sala Plena se encuentra en la reflexión sobre el artículo 76, numeral 18, de la Constitución de $\mathbf{1 8 8 6}$ y sobre la posible existencia de derecho comunitario. Si bien con el Acto Legislativo 1 de 1968 se facultó al Congreso de la República para que no sólo ratificara tratados internacionales, sino también para obligar al Estado colombiano a crear instituciones que tengan por objeto promover o consolidar la integración económica con otros Estados; la CSJ-Sala Plena se cuestiona si dicha norma faculta o permite que en el Estado colombiano, además de la existencia del derecho nacional, pueda hablarse de la de un derecho comunitario, con normas autónomas producidas por los órganos supranacionales reconocidos en el Acto Legislativo 1 de 1968, que reforma el artículo 76, numeral 18, de la Constitución de 1886.

Sin reflexiones previas, la CSJ-Sala plena niega la posibilidad de la existencia del derecho comunitario. Según esta corporación, en sentencia del 26 de julio de 1971 y ratificada en sentencia del 20 de enero de 1972,

[n]i se diga que existe un derecho de las comunidades internacionales, conforme al cual ciertas estipulaciones de tipo económico consagradas en pactos multilaterales, por elásticas, dan vida, así como así, a organizaciones diferentes y les confieren poderes superiores a los que son ajenos de ordinario a los Estados, aisladamente considerados, en el manejo de sus asuntos exteriores; ese derecho no existe, ni por semejas. [...] Invocar nociones tan vagas como las aquí traídas en refuerzo de la validez, sin aprobación del Congreso, del Pacto Andino, cuya tabla de competencias no ha sido consagrada por todos los órga- nos idóneos del Estado nacional, es argüir en sentido contrario a la Constitución, a los procedimientos del derecho colombiano, a los cuales remite, por lo demás, el propio Acuerdo de Cartagena (artículo 110).

En síntesis, CAN, en términos de las dos primeras sentencias de la CSJ-Sala Plena, es un instrumento internacional autónomo que no ejecuta el Tratado de Montevideo. Aunque su incorporación al derecho interno ha sido contrario a la cláusula de competencias de la Constitución de 1886 , no era posible para la CSJ juzgar su exequibilidad, pues ello implicaría argumentar el incumplimiento de un acuerdo internacional que los demás Estados firmantes aceptaron. Por último, la creación de instituciones supranacionales reconocidas en la Constitución de $\mathbf{1 8 8 6}$ no implica la existencia de un derecho comunitario, pues la expedición de normas, la determinación de entrada en vigencia de otras, son competencias que la Constitución de 1886 ha consagrado como exclusivas de órganos nacionales.

\section{El cambio de entendimiento del Pacto Andino en la Corte Suprema de Justicia}

La CSJ-Sala Plena, en su tercer pronunciamiento sobre la CAN, mantuvo las tesis de competencias constitucionales y de formulación de actos complejos. Sin embargo, cambió su postura respecto al entendimiento del Acuerdo de Cartagena y la posibilidad de un derecho comunitario.

Mediante el estudio de algunos apartados de la Ley $8^{a}$ de 1973 , por medio de la cual se ratificaba el AC, la CSJ de justicia es clara al mencionar que, de acuerdo con lo consagrado en el artículo 76, numeral 18, de la Constitución, es el Congreso quien debe aprobar los tratados internacionales, especialmente aquellos que creen órganos supranacionales. Asimismo, se confirma -como lo hacen las dos sentencias anteriores- que la CS] no es competente para estudiar casos de constitucionalidad de tratados internacionales, y que la 
Ley $8^{\text {a }}$ de 1973 constituye un acto complejo -esta vez legislativo- compuesto de una norma que ratifica un tratado internacional que no puede ser objeto de análisis, y por normas proferidas por el legislador que son propias de su ejercicio habitual; por tanto, su decisión sólo tocará aquellas normas que correspondan a ese ejercicio habitual.

El derecho comunitario, en esta ocasión, es entendido por la CSJ a través de tres cuestiones básicas: a) el efecto de las normas proferidas por órganos andinos; b) la necesidad de ley que ratifique cada acto proferido por órganos andinos, y c) alternativas en caso de existir una norma proferida por órgano andino que fuese contraria a la Constitución. EI punto de partida de la CSJ-Sala Plena es el cumplimiento estricto y en buena fe de los tratados internacionales. Si un tratado internacional es negociado, firmado y ratificado adecuadamente por el Estado Colombia, según el artículo $1^{\circ}$ de la Ley de 1944, esto obliga a su cumplimiento, que debe realizarse con estrictez y buena fe; es decir, no se puede argumentar constitucionalmente que, posterior a la entrada en vigencia del tratado internacional, el Estado colombiano ignore sus obligaciones. Además, debe tenerse en cuenta que tampoco es viable su desconocimiento, porque el tratado internacional tiene fuerza de ley. Estos criterios son aplicables al Acuerdo de Cartagena, pues su ratificación se realizó mediante órgano competente -Congresoy existió una etapa de negociación y de canje de notas realizadas por el Ejecutivo. Por tanto, las reglas de cumplimiento del AC como tratado internacional son aplicables, y las disposiciones consagradas en él deben cumplirse con estrictez y buena fe.

De acuerdo con estas afirmaciones, y conforme al AC, la CSJ-Sala Plena determinó que los actos proferidos por la Comisión y la Junta, como órganos supranacionales comunitarios, tienen efectos en todos los países miembros de la CAN, que son su procedimiento propio -mérito propio- y su aplicación directa, salvo que el mismo AC prevea alguna otra forma.
Si las normas proferidas por la Comisión o la Junta se aplican directamente, es de cuestionarse si requieren de un acto intermedio o de validación para su vigencia en el territorio nacional. Para la CSJ-Sala Plena, no existe norma expresa en el Acuerdo de Cartagena que establezca que las normas proferidas por órganos comunitarios deban aprobarse por el Legislativo o el Ejecutivo. Afirmar que aquellas requieran de una aprobación por parte del órgano legislativo colombiano sería contrariar las disposiciones del AC y, por ende, una violación a las reglas de cumplimiento de los tratados internacionales. En otras palabras, los actos proferidos por las instituciones de la CAN tienen un efecto directo, que se conoce, actualmente, como una de las características propias del derecho comunitario.

Aunque puede hablarse de una aplicación directa e inmediata de las normas proferidas por las instituciones supranacionales, la CSJ-Sala Plena se cuestiona, por último, cuáles son las alternativas que tiene el Estado colombiano en caso de existir una norma comunitaria contraria a la Constitución o al derecho interno. Aunque el derecho colombiano no puede desconocer las normas contenidas en el AC en virtud de la obligación de cumplimiento en estrictez y buena fe de los tratados, ello no implica que, en términos de la CSJ, se deban cumplir o ejecutar las que contravengan la Constitución. Para ello existe, según la CSJ-Sala Plena (1975), el ejercicio de un control de corrección jurídica aplicable $y$, en caso de encontrarse una norma contraria, el gobierno debe negociar las modificaciones a que hubiere lugar, o denunciarlo, en acatamiento a la norma fundamental de su derecho público.

Aunque la CSJ no hace mención expresa a un derecho comunitario como tal -a diferencia de las sentencias proferidas en 1971 y 1972-, ella reconoce efectos que son propios del mismo, es decir, inmediatos y directos de las normas proferidas de las instituciones del Pacto Andino. Asimismo, la CSJ-Sala Plena entiende que a las instituciones del Pacto Andino les es aplicable la expresión 
"instituciones supranacionales", consagrada en el artículo 76 de la Constitución de 1886 y que se comportan de forma autónoma o independiente a las instituciones del derecho interno colombiano. Por tanto, no pueden gozar un tratamiento similar que una ley o un acto administrativo proferidos por órganos colombianos.

\section{La experiencia de la Comunidad Andina (Pacto Andino) hasta la Constitución Política de 1991}

La experiencia de la CAN desde el aspecto constitucional pareciese no tener, pese a las discusiones internas de la CSJ-Sala Plena, mayor complicación en cuanto a su incorporación en el territorio coIombiano. Especialmente, su ingreso fue, si es posible decirse, fácil gracias a la reforma constitucional consagrada en el Acto Legislativo 1 de 1968, y al respeto por la vigencia y cumplimiento de obligaciones surgidos de tratados o instrumentos internacionales. Sin embargo, desde la experiencia fáctica, se puede decir que el funcionamiento de la CAN no contó con el éxito esperado y, por el contrario, se enfrentó a distintos problemas, especialmente de índole económico, reflejados en las crisis de deuda externa de algunos de los Estados miembros de la CAN"11.

La situación de la integración sub-regional andina puede entenderse desde su producción normativa (Vallenas M., 2008: 3 y ss.) y desde su funcionamiento como bloque regional a través del concepto de regionalismo.

Desde la producción normativa, previa a la Constitución Política de 1991, se produjeron en el interior

11 Para Vallenas (2008), el Pacto Andino ha constituido proceso de constantes fracasos, especialmente por las crisis no sólo de deuda externa que vivieron algunos de los Estados miembros del Acuerdo de Cartagena, sino también por la experiencia vivida en las crisis del precio del petróleo, de las cuales se esperaba la realización de acciones tendientes a apoyar a los Estados del Pacto Andino. Sin embargo, no existió una acción conjunta, sino la participación aislada de países como Venezuela y México (Vallenas, 2008: 3), así como una actuación individual de cada Estado para la estabilización de la balanza de pagos. de la CAN 278 decisiones, de las cuales sólo un porcentaje mínimo se encaminaba a la regulación de temas de armonización de políticas o de operaciones en el espacio sub-regional andino (Vallenas M., 2008: 3 y ss.), mientras que la mayoría de las decisiones se encaminaban bien sea a crear consejos consultivos, aprobación de presupuestos, entre otros temas ${ }^{12}$. Quizás sean de mención especial el Tratado de la Paz de 1979 y el Tratado del Tribunal de Justicia de la Comunidad Andina (en adelante TJCAN) de 1979. En el primero, la CAN incorpora al sistema de integración el Parlamento Andino, que consagra en su artículo 12, lit. c), la función de velar por el cumplimiento de los derechos humanos. Con el Tratado del TJCAN, que entró en vigencia en 1983, se constituye el órgano jurisdiccional que dirime las diferencias surgidas entre los Estados miembros y la CAN (García de C., 1999: 72).

Desde el concepto regionalismo, la CAN funcionó de forma cerrada ${ }^{13}$. Durante los primeros años -hasta mediados de los ochenta-, la CAN (Pacto Andino) cerró la posibilidad de una interacción del bloque y de sus países miembros con la comunidad internacional. Ello lo realizó mediante la implementación del programa de sustitución de importación, que consiste en el fortalecimiento de las industrias nacionales (Fuentes F., 2008: 177 y ss.) a fin de producir los bienes necesarios para la región, de modo tal que no es necesaria la importación de bienes de países no pertenecientes a la CAN y, así, se fomentaría el comercio entre los países miembros.

Sin embargo, tanto la producción de normas como la aplicación de un modelo cerrado de regiona-

12 Esta situación pareciese para Barbosa M. (1972) no ser un indicador negativo, teniendo en cuenta que la producción inicial de normas -y el poco tiempo transcurrido- por parte del Pacto Andino, produjeron ventajas significativas en el comercio subregional, especialmente en materia de beneficios para productos industriales, liberalización de comercio, disminución de aranceles, programa sectorial, situación petroquímica, entre otros.

13 El regionalismo indica cómo un bloque regional funciona, entre otros, desde su proyección externa; es decir, en cuanto a las relaciones comerciales internacionales con Estados no pertenecientes al bloque. 
lismo no resultaron en sí una estrategia efectiva para los primeros años de la CAN. Los problemas centrales para que su diseño no funcionara fueron el incumplimiento de los compromisos adquiridos en los programas de desgravación de productos (Lamelas C.; Aguayo L.; Cancelo M., 2005: 3) y la crisis de deuda externa de los Estados miembros, quienes estuvieron obligados a la búsqueda de su liberalización de comercio (Creamer, 2004: 47 y ss.; Acosta R., Gina; Galfat, Germán; Flôres Jr., Renato, 2006).

Ello llevó a que la CAN, mediante el Protocolo de Quito, reformase el capítulo II del Acuerdo de Cartagena, el cual buscó que el Bloque Regional Andino se basara en un mayor aprovechamiento de los mercados y recursos propios (Carmona, 1988: 7), teniendo en cuenta factores como la reducción de los niveles de proteccionismo y la búsqueda de créditos e inversión en los países miembros de la CAN. Dicha intención se vio, desde la perspectiva colombiana, con el cambio del artículo $7^{\circ}$ del AC y la redacción de la Constitución Política de 1991 (apartado II). El artículo $7^{\circ} \mathrm{del}$ AC, reformado por el Protocolo de Quito, estableció, a diferencia del artículo original, el fortalecimiento de la integración de la región y la proyección externa de la CAN. Ello significa que la CAN busca el mejoramiento de la calidad de vida de los habitantes de los Estados miembros y de los niveles macroeconómicos de Ios mismos, teniendo en cuenta que es necesario, para ello, la celebración de negociaciones del bloque con Estados terceros.

\section{LA EXPERIENCIA DE LA COMUNIDAD ANDINA EN LA CONSTITUCIÓN POLÍTICA DE 1991}

\section{A. Disposiciones normativas sobre integración en la Constitución Política de 1991}

La entrada en vigencia de la Constitución Política de 1991 (en adelante Constitución de 1991) trajo cambios significativos en las relaciones de los ciu- dadanos con el Estado, mediante la formulación de un catálogo de derechos fundamentales, derechos sociales -económicos y culturales- y derechos económicos y de medio ambiente. Asimismo, la Constitución de 1991 trajo, mediante sus artículos 113 , ss. y concordantes, reformas interesantes en la formación y funcionamiento del Estado, especialmente por el reconocimiento expreso de la participación de particulares en la administración de justicia como conciliadores o árbitros -art. 116 Constitución de 1991-.

En materia de integración regional, la Constitución de 1991 consagra también reformas significativas encaminadas, básicamente, a: a) consagrar un reconocimiento expreso del proceso de integración, especialmente el latinoamericano, y b) evitar conflictos de competencia interna, como lo expuso la CSJ-Sala Plena, especialmente en materia de incorporación y vigencia de los tratados internacionales.

El artículo 9 de la Constitución de 1991 establece en su inciso $2^{\circ}$ que la política exterior de Colombia se orientará hacia la integración latinoamericana y del Caribe. Este artículo es reforzado por el 227 de la Constitución de 1991 al establecer que el Estado promoverá la integración económica, social y política, especialmente con los países de América Latina y del Caribe, mediante la celebración de tratados que creen organismos supranacionales, inclusive para conformar una comunidad latinoamericana de naciones.

El artículo 150, numeral 16, establece como competencia del Congreso aprobar los tratados que celebre el gobierno con otros Estados o entidades de derecho internacional, los cuales pueden transferir parcialmente determinadas atribuciones a organismos internacionales, que tengan por objeto promover o consolidar la integración económica con otros Estados. Esta redacción deja una duda respecto al límite de transferencia de atribuciones. Si bien puede entenderse que son similares las expresiones organismos supranacionales y orga- 
nismos internacionales -o que el primero es una especie del segundo y que el Constituyente evitó ser excluyente con el uso del primer término-, la Constitución es clara al determinar que dichos organismos sólo podrán tener competencias siempre y cuando se hable de una integración regional, dejando a un lado las integraciones social y política que consagra la misma Constitución de 1991 en su artículo 227. Por tanto, es de cuestionarse si, en caso de la existencia de un proceso de integración, cuyo objeto no es económico, sino social o político, podría o no el Congreso transferir competencias. Esta cuestión no es aplicable al Bloque Regional Andino, pues la modalidad esencial consagrada por el Acuerdo de Cartagena, en su artículo $1^{\circ}$, es una integración -y cooperacióneconómica; por tanto, y desde una lectura inicial, las instituciones de la CAN pueden ser objeto de transferencia de atribuciones según el artículo 150, numeral 16, de la Constitución de 1991. Además, la jurisprudencia de la Corte Constitucional, en el estudio de constitucionalidad de los instrumentos de la CAN, tiene como soporte jurídico los artículos 20, 9 y 227 de la Constitución de 1991 y, aunque algunos de los instrumentos incorporaron asuntos como democracia y elecciones de parlamentarios andinos -que podrían considerarse integración política-, la Corte Constitucional hace énfasis en la aplicación del trato preferencial que gozan los procesos e instituciones encaminados a una integración latinoamericana. Por tanto, los artículos $9^{\circ}$ y 227 de la Constitución de 1991 tienen prioridad -en los análisis de la Corte Constitucional- sobre el artículo 150, numeral 16.

Otros dos artículos de mención especial son los relacionados con la vigencia de los tratados internacionales en Colombia y con la promoción de las relaciones internacionales en sus distintos campos. El artículo 224 de la Constitución de 1991 consagra como regla general que los tratados entrarán en vigencia una vez el Congreso los ratifique. Sin embargo, en asuntos económicos y comerciales -acordados en el ámbito de orga- nismos internacionales-, la Constitución permite que el Presidente dé aplicación provisional a los tratados y, en caso que, posteriormente, no sean aprobados por el Congreso, deben suspenderse. Esta regla, que no se encontraba en la Constitución de 1886, resuelve dos cuestiones centrales en la jurisprudencia de la CSJ-Sala Plena en el análisis de la Constitución de 1886: a) competencias en materia de incorporación de instrumentos internacionales; b) efectos de la no aprobación de un tratado que se encuentra en vigencia. Por una parte, aunque la Constitución de 1991 es clara en materia de aprobación de tratados, permite que sólo en casos económicos o comerciales la incorporación del instrumento internacional sea mediante acto administrativo. En este sentido, mientras que para la Constitución de 1886 existía una violación expresa de los mandatos constitucionales, en la de 1991 existe una legitimación para que el gobierno incorpore un instrumento y no haya una violación de competencias constitucionales. Por otra parte, la Constitución de 1991 evita el debate surgido sobre la no aprobación de un tratado en vigencia. Si bien para la CSJ-Sala Plena la Corte no podía fallar la constitucionalidad de un tratado en vigencia, argumentando la violación de principios de derecho internacional público, la Constitución de 1991 consagra la solución que debe adoptar el Estado colombiano, es decir, la suspensión de la vigencia del tratado internacional. Ello implica que el Estado no desconoce la vigencia de un tratado internacional, sino que, mediante el uso de los procedimientos propios del derecho internacional público, buscará las alternativas adecuadas para armonizar las normas constitucionales con el instrumento internacional.

Por otra parte, el artículo 227 de la Constitución de 1991 establece que Colombia promoverá la internacionalización de las relaciones políticas, económicas, sociales y ecológicas sobre bases de equidad, reciprocidad y conveniencia nacional. Este artículo, que concuerda con el $7^{\circ}$ del Acuerdo de Cartagena -reformado por el Protocolo de Qui- 
to-, descarta el posible uso de un regionalismo cerrado nuevamente y determina que el Estado solo actuará bajo una proyección internacional, permitiendo negociaciones internacionales con Estados terceros a los procesos de integración -en este caso la CAN-, la búsqueda de inversión extranjera en Colombia, entre otros.

\section{B. La jurisprudencia de la Corte Constitucional de Colombia respecto a la Comunidad Andina}

A diferencia de la CSJ-Sala Plena, la Corte Constitucional ha tenido mayores oportunidades de manifestarse en torno a la relación entre la Constitución de 1991 y los instrumentos de la CAN. Si bien no tuvo la oportunidad de estudiar la constitucionalidad del Acuerdo de Cartagena directamente, ha podido analizar la de instrumentos que han hecho reformas significativas en él, como el Protocolo de Trujillo o el Protocolo Compromiso de la Comunidad Andina de la Democracia, los cuales permitieron el estudio de temas esenciales de la estructura, contenido y funcionamiento del derecho comunitario.

Básicamente, la Corte Constitucional definió las relaciones del ordenamiento jurídico colombiano con el jurídico comunitario a través de diez pronunciamientos, de los cuales cuatro son autos y seis son sentencias de constitucionalidad ${ }^{14}$. Sin embargo, se puede decir que el primer pronunciamiento de la Corte Constitucional sobre la CAN lo hizo -aunque no fue el objeto de estudio- en la Sentencia de Constitucionalidad C-137 de 1996. Allí, donde se estudió como tema central la protección de derechos fundamentales frente a la regulación internacional y comunitaria, la Corte Constitucional aborda, por primera vez ${ }^{15}$, los conceptos de supra-

14 Corte Constitucional, sentencias de constitucionalidad C-227 de 1999; C-231de 1997; C-334 de 2002; C-581 de 2002; C-644 de 2004 y C-864 de 2006.

15 Es de anotar que, desde la perspectiva del derecho administrativo y del derecho comunitario, existieron pronunciamientos, del Consejo de Estado y del Tribunal de Justicia de la Comunidad nacionalidad y efectos del derecho comunitario ${ }^{16}$ Sobre la supranacionalidad, la Corte Constitucional (C-137 de 1996) explica que es un fenómeno que implica el desprendimiento de ciertas atribuciones nacionales, mediante tratado internacional, que asume una organización internacional, quien adquiere competencia para regular de manera uniforme para todos los países miembros sobre materias determinadas. Esta regulación, en términos de la Corte Constitucional, tiene dos efectos: a) de inmediatez -efecto inmediato-, que les permite a las personas solicitar directamente a los jueces nacionales la aplicación de norma supranacional, y b) de prevalencia, que implica, en caso de conflicto entre norma supranacional y nacional, el desplazamiento de esta a favor de aquella. Asimismo, es de anotar que tanto las implicaciones de la supranacionalidad y sus efectos están fundamentados, de acuerdo con la Corte Constitucional (C-137 de 1996) en los artículoss 9o, 150 numeral 16 y 227 de la Constitución de 1991, de los cuales la Corte resalta el encaminamiento del Estado colombiano a una integración con preferencia a Latinoamérica -arts. $9^{\circ}$ y 227 de la Constitución de 1991 - y la atribución de competencias -art. 150 de la Constitución de 1991-.

Esta sentencia influye en los demás pronunciamientos de la Corte Constitucional -especialmente en la Sentencia de Constitucionalidad C-231 de

Andina, previos a los de la Corte Constitucional y que ya definían la naturaleza del derecho comunitario y sus relaciones con el derecho nacional. Dichos pronunciamientos fueron el concepto del Consejo de Estado, Sala de Consulta y Servicio Civil, del 6 de septiembre de 1979 -consejero ponente Jaime Paredes Tamayo-, y la Sentencia de Interpretación Prejudicial 01-IP-87 del Tribunal de Justicia de la Comunidad Andina. Sobre el entendimiento del derecho comunitario desde la perspectiva de la jurisprudencia del Tribunal de Justicia de la Comunidad Andina de Naciones, se recomiendan los trabajos de Tremolada (2006-07) y de Quindimil L. (2006).

16 Sin embargo, la Corte Constitucional no ha realizado un análisis profundo sobre la conformación, funcionamiento y fuentes del derecho comunitario. Para una explicación se recomienda a Tremolada (2006-07) quien, a partir del análisis del Tratado Constitutivo del TJCAN y su Protocolo modificatorio, expone la composición de las fuentes de derecho comunitario desde la perspectiva jerárquica y orgánica. 
1997-, los cuales pueden dividirse en tres grupos: a) la naturaleza y características del derecho comunitario ${ }^{17}$; b) la vigencia de valores constitucionales en su relación con el derecho comunitario ${ }^{18}$, y c) las relaciones de la CAN con agentes terceros ${ }^{19}$.

La Corte Constitucional, al referirse al derecho comunitario, trató básicamente tres aspectos: a) composición del derecho comunitario, b) efectos del derecho comunitario y c) tribunal competente del derecho comunitario. Para la Corte, el derecho comunitario de la CAN no es uno simple que se oriente a una cooperación, sino hacia la integración (C-231 de 1997), y que no se desarrolla simplemente a través de tratados, protocolos o convenciones, sino también a través de las normas emitidas por los órganos comunitarios dotados de competencias para ello. Por tanto, se entiende que el derecho comunitario está compuesto de un derecho primario -tratados internacionales- $y$ de uno secundario -normas proferidas por los órganos competentes-. El derecho secundario goza, a su vez (C-231 de 1997 y C-227 de 1999), de aplicación directa -obligatoriedad de la norma desde su promulgación, salvo excepción propuesta por la misma norma- y de prevalencia sobre el derecho nacional -característica desarrollada por la Sentencia de Constitucionalidad C-137 de 1996- ${ }^{20}$. Estos efectos, en términos de la Corte Constitucional, ya encontraban sustento en el ordenamiento jurídico colombiano no sólo a través de la Sentencia C-137 de 1996, sino también de la CSJ-Sala del 27 de febrero de 1975, la cual estudió la constitucionalidad de la Ley $8^{\text {a }}$ de 1973 -aprobación del Acuerdo de Cartagena- (véase apartado I) y, por tanto, la labor de la Corte Constitucional es simplemente de reiterar la existencia y vigencia de los efectos

17 Sentencias de Constitucionalidad C-231 de 1997 y C-227 de 1999.

18 Sentencias de Constitucionalidad C-227 de 1999 y C-644 de 2004.

19 Sentencias de Constitucionalidad C-334 de 2002, C-581 de 2002 y C-864 de 2006.

20 A estos dos efectos, es necesario agregarle el de inmediatez, desarrollado por la Corte Constitucional en Sentencia de Constitucionalidad C-137 de 1996 y mencionada anteriormente en este escrito. que gozan las normas comunitarias. Asimismo, la Corte Constitucional aporta una característica al derecho comunitario -y que relaciona directamente al Tribunal de Justicia de la Comunidad Andina-, conocida como aplicación uniforme del derecho comunitario. Las normas proferidas por los órganos regionales no pueden ser interpretadas por cada uno de los países miembros del Bloque Regional, pues ello implicaría una posible aplicación diferente, e incluso contradictoria, de las disposiciones comunitarias. Por tanto, es necesaria la existencia de un tribunal especializado que, en términos de la Corte Constitucional (C-227 de 1999), permita la interpretación uniforme y la aplicación homogénea del derecho comunitario, mediante providencias que determinen el contenido y alcance del mismo. En caso de no existir dicho tribunal, se correría el riesgo de que, a través de interpretaciones y aplicaciones diferentes -atomización de interpretación-, surjan situaciones de inequidad, desvirtuando así el proceso de integración.

La segunda cuestión que trata la jurisprudencia de la Corte Constitucional se relaciona con la proyección y protección de los valores constitucionales en el proceso de integración regional, en este caso de la CAN. Dicho análisis se hizo en virtud de la incorporación del Protocolo de Trujillo -Ley 323 de 1996- y del Protocolo Compromiso de la Comunidad Andina por la Democracia -Ley 846 de 2003-, y tratan en especial de: a) el principio de separación de poderes (C-227 de 1999); b) el principio democrático (C-644 de 2004), y c) la protección de derechos fundamentales (C-227 de 1999).

Los puntos centrales de la Corte Constitucional para el estudio de estos protocolos cuentan con la profundización en el proceso de integración y el reconocimiento de principios democráticos. Un requisito esencial para poder contar con una integración profunda es la participación directa de cada uno de los participantes del proceso en la misma, es decir, de la ciudadanía, de los Estados y de la misma integración. Dicha participación, 
en concepto de la Corte Constitucional, sólo es posible mediante la creación de instituciones comunitarias que permitan la intervención de cada uno de los actores (C-227 de 1999) ${ }^{21}$. Dichas instituciones no cumplen las mismas funciones, sino que, mediante la separación de poderes y en virtud de la representación de los intereses de cada uno de los actores, ejercen unas competencias -limitadas- independientes, pero que al mismo tiempo están armonizadas y orientadas al cumplimiento de metas u objetivos comunes. Por ello, la creación de instituciones como el Parlamento Andino, el Consejo de Ministros de Relaciones Exteriores y la reforma al Tribunal de Justicia, constituyen en sí la representación de los actores -ciudadanos, Estados e integración- y el respeto de sus intereses, mediante la prohibición de ejercer competencias no consagradas en los tratados constitutivos ni en la imposición de tareas entre los órganos de la CAN.

Aunque la creación de nuevas instituciones y la división de competencias están conforme a lo establecido en la Constitución, la Corte Constitucional se cuestiona si un proceso de integración, en este caso la CAN, puede imponer un régimen al Estado colombiano, como lo hizo en el Protocolo Compromiso de la Comunidad Andina por la Democracia. Para la Corte (C-644 de 2004), si bien la Constitución de 1991 establece que Colombia es democrática, esta Carta, en el artículo 9, consagra como principios orientadores de las relaciones internacionales la autodeterminación y la soberanía popular. El principio de la autodeterminación, según la Corte Constitucional, tiene como una de sus expresiones la independencia política, la cual le permite a cada Estado decidir, de forma autónoma, sobre asuntos internos y externos al mismo, es decir, sin injerencia de otros actores.

21 Un énfasis especial hace la Corte Constitucional (C-227 de 1999) en la vinculación de los poderes ejecutivos al proceso de integración, pues son ellos quienes, mediante una acción constante y conjunta, pueden realizar la dirección de una política clara que permita la realización de las metas propuestas en la integración.
La forma de decidir sobre dichos asuntos se sustenta en la adopción que hace cada Estado de su régimen político -así como de su organización y su forma de gobierno-. Dicha adopción se hace mediante el ejercicio de la soberanía popular, que establece que es el pueblo quien escoge libremente la composición y funcionamiento del Estado. Esta elección se realiza mediante el ejercicio del poder constituyente primario, es decir, mediante la formación de la Constitución, y ningún órgano del Estado, especialmente el Legislativo, podrá modificar dicha elección (C-644 de 2004).

Sin embargo, la Corte Constitucional (C-644 de 2004) encuentra dos argumentos para apoyar la exequibilidad de la Ley 846 de 2003: a) la idoneidad de la democracia, y b) la universalidad y expansión de la democracia. Por una parte, para la Corte la forma democrática de gobierno es adecuada no sólo para regir las relaciones entre hombres, sino también para adquirir compromisos internacionales, pues supone el respeto de los principios de libertad y autonomía, que pueden aplicarse a la integración. Por otra parte, existe una tendencia a la expansión de la democracia y sus valores, pues ella responde la exigencia de buscar patrones comunes que permitan comprometer la voluntad de los Estados, en el desenvolvimiento de reglas claras y acordes con la ideología política de la organización estatal (C-644 de 2004). El uso de la democracia exige la solución pacífica de controversias -mediante la prohibición de agresión-, que permite una protección de las libertades fundamentales y facilita la práctica de las relaciones comerciales. Sin embargo, aclara la Corte Constitucional que, pese a existir argumentos en pro de la aprobación de la Ley 846 de 2003, debe recordarse que, en ningún momento, en virtud de las relaciones internacionales, se puede imponer, de forma autoritaria, el establecimiento de un régimen político, pues ello atentaría contra los valores constitucionales.

La tercera cuestión tratada por la Corte Constitucional, en virtud de la proyección y protección de 
valores constitucionales, consiste en las consecuencias de una posible afectación negativa de derechos fundamentales. Para la Corte Constitucional es claro que el único órgano competente para conocer sobre el contenido y alcance de las normas comunitarias es el Tribunal de Justicia de la Comunidad Andina; sin embargo, puede llegar a existir el caso en que una de esas normas desconozca o atente contra un derecho fundamental. En este evento, la Corte podría (C-231 de 1997) decidir la inaplicabilidad de la norma comunitaria, siempre y cuando se haya pedido al Tribunal de Justicia de la Comunidad Andina que determine el alcance de dicha norma -y de manera implícita, que tal interpretación efectivamente atenta o desconoce un derecho fundamental-. Asimismo, esta posibilidad se cerraría en el caso en que, en la normativa del Tribunal de Justicia de la Comunidad Andina, se consagrase un procedimiento efectivo que garantizara la protección de derechos fundamentales (C-231 de 1997).

El último tema de análisis de la Jurisprudencia de la Corte Constitucional consiste en las relaciones entre la CAN y agentes terceros, bien sean Estados o bloques regionales a través de las sentencias de constitucionalidad C-581 de 2002 y C-864 de 2006, que estudian los acuerdos de alcance parcial de complementación económica entre Argentina y los países de la CAN, y de Brasil con los mismos. Lo importante de estas sentencias se encuentra en la proyección internacional que le da la Corte Constitucional al ordenamiento jurídico. Para la Corte, si bien los artículos 9o y 227 de la Constitución Política dan un trato preferencial a los procesos de integración, ello no implica, en el entender de la Corte (C-864 de 2006), que Colombia no pueda participar en la consolidación de relaciones comerciales internacionales con otros Estados, pues el artículo 226 de la Constitución de 1991 es clara al establecer que Colombia promoverá la internacionalización de las relaciones económicas -entre otras-. Por tanto, las acciones que realice el
Estado colombiano, bien sea por iniciativa propia o a través de la CAN, encuentran pleno respaldo en la Constitución colombiana, especialmente cuando el fortalecimiento de las relaciones tiene como actores países de Latinoamérica. En otras palabras, lo que busca la Constitución de 1991 y la Corte Constitucional es evitar que se use nuevamente una modalidad de regionalismo cerrado (véase apartado I), donde sólo existía una relación comercial con los países miembros de la CAN y donde se implementó un sistema de sustitución de importaciones que resultó inadecuado para el proceso de integración, desplazándose así a una tendencia de regionalismo abierto, donde les es posible a los Estados participar de manera activa en el comercio internacional y crear espacios adecuados para la inversión extranjera.

\section{La cuestión de prioridad del Bloque Regional Andino en la normativa constitucional}

Con las reformas en la CAN a mediados de los ochenta, la entrada en vigencia de la Constitución de 1991 y la jurisprudencia de la Corte Constitucional, especialmente hasta el 2002, se puede decir que el Bloque Regional Andino gozó de un impulso que le permitió avanzar en ciertos temas de la integración. Gracias a las reformas, durante los primeros años de los noventa la CAN vivió una participación activa de los presidentes, especialmente de los Estados de Colombia y Venezuela, en las mejoras de los diseños políticos para el funcionamiento adecuado del mercado andino (Milanese, 2005: 101). Asimismo, los empresarios colombianos y venezolanos, quienes se encontraban de espaldas hasta esa década, decidieron, gracias a las iniciativas intergubernamentales, desarrollar lazos para un mejoramiento del comercio ente ambos países, llegando a ser quienes aportasen la mayor parte de ingresos en el comercio intra-zona y quienes representaron un flujo de exportaciones del aproximadamente 50\% de la CAN (Milanese, 2005: 104). 
Sin embargo, la jurisprudencia de la Corte Constitucional influyó también en la no continuidad -avanzada- de las exportaciones entre Colombia y Venezuela, en la intra-zona. Dicha influencia se vio en la interpretación que dio la Corte Constitucional sobre la prioridad que tiene el proceso de integración andino sobre otros procesos, especialmente con países que no corresponden a Latinoamérica y el Caribe. Un ejemplo se puede encontrar en la Sentencia de Constitucionalidad C-864 de 2006, en la cual la Corte Constitucional se cuestionó, entre otros, sobre la participación de Colombia en escenarios que no corresponden al proceso de integración andino. Para la Corte Constitucional, debe tenerse en cuenta que, conforme a los artículos 226 y 227, existen distintos tipos de integración (C-864 de 2006): a) los simples acuerdos bilaterales, b) los acuerdos de integración -como el G3 y la CAN- y c) los acuerdos de complementación económica, suscritos en virtud del ALADI.

Entre estas modalidades de integración, la Corte Constitucional encuentra que la Constitución faculta al Estado colombiano bien sea a negociar con Estados latinoamericanos, conforme a los artículos $9^{\circ}$ y 227 de la Constitución de 1991, o bien a negociar con otros Estados, de acuerdo con los artículoss 226 y 227 de la misma Carta. Asimismo, la Corte Constitucional no encuentra, entre las distintas modalidades, una prevalencia especial, es decir que todas ellas gozan del mismo valor, pues permiten la realización de los fines propuestos por la Constitución de 1991. Sin embargo, es de anotar que la Corte Constitucional, en el estudio de prevalencias, omite los apartados de los artículos $9^{\circ}$ y 227 , que consagran un trato preferencial para los países de América Latina y del Caribe, como un sustento normativo para dar prioridad al Bloque Regional Andino y sus reglas de integración, especialmente en lo concerniente a las negociaciones comerciales en bloque, pues, en palabras de la Corte Constitucional,
[...] esto no significa que una dirección contraria en el manejo de las relaciones internacionales, como ocurriría en el caso en que se privilegie los acuerdos económicos con otras naciones del mundo distintas a las que integran la región de América Latina sean per se inconstitucionales, pues lo que la Carta Fundamental establece, a juicio de esta Corporación, es un mandato de preferencia en la orientación de las relaciones internacionales y no una camisa de fuerza en el desarrollo de las mismas (C864 de 2006).

El efecto práctico de esta consideración por parte de la Corte Constitucional se manifiesta en: a) las excesivas negociaciones bilaterales que tiene actualmente el Estado colombiano ${ }^{22}$, y b) el trato secundario que ha venido teniendo la CAN. Esto produjo que otros países del Bloque Regional Andino no encuentren un respaldo en él y hayan buscado otras alternativas como Mercosur. Tal es el caso de Venezuela, quien después del inicio de las negociaciones de Colombia con Estados Unidos por el desarrollo del Plan Colombia (Milanese, 2005: 107 y ss.) y de la búsqueda de un tratado de libre comercio con el mismo país ${ }^{23}$, haya decidido abandonar la CAN por no encontrar en ella un proyecto de integración estable, pues

22 Colombia cuenta en la actualidad con los siguientes tratados: (a) el Acuerdo Comercial con la República de Polonia (C-280 de 1994); (b) el Convenio Comercial con la República de Hungría (C-216 de 1996); (c) el Acuerdo Comercial con la República Checa (C-323 de 1997); (d) el Acuerdo de Comercio con la República de Malasia: (e) el Acuerdo Comercial con la República Argelina Democrática y Popular (C-228 de 1999); (f) el Convenio Comercial con la Federación Rusa (C-405 de 1999); (g) el Acuerdo Comercial con el Reino de Marruecos (C-719 de 1999); (h) el Acuerdo Comercial con la República de Rumania (C-327 de 2000), y finalmente (i) el Acuerdo Comercial con la República de Costa de Marfil (C-279 de 2001).

23 Este ha sido, para la mayoría de los autores, el principal problema que tiene en la actualidad el proceso de integración andino. Por una parte, permitir la participación de Estados Unidos en un conflicto interno colombiano cuestiona la posible intervención de Norteamérica en asuntos internos de otros Estados. Por otra parte, la intervención de Estados Unidos implicaba una contradicción con la perspectiva de integración de Venezuela, para quien la integración tiene también una dimensión militar y soberana. Para un análisis de los problemas y efectos en la CAN, se recomiendan los estudios de Vela (2006-07), González (2008), Barbosa (1972), Casas y Correa (2007), y Fuentes (2006-07). 
no goza, como lo hace la Unión Europea, de un trámite preferencial o prioritario sobre los demás acuerdos internacionales.

Ello significa que la CAN dejó de ser un escenario con tendencias exportadoras y haya tendido hacia una baja en cuanto a la importancia que tiene como actor en el comercio internacional. Asimismo, esta tendencia manifiesta que el proceso de integración andino camina en dos direcciones al mismo tiempo. Por un lado, desarrolla una estructura institucional avanzada, con órganos con competencias especializadas y con un Tribunal de Justicia que tiene un papel importante en la unificación de criterios sobre las normas comunitarias. Por otro lado, la CAN tiende a un detrimento en cuanto a las relaciones comerciales entre los países miembros y hacia una búsqueda de nuevas relaciones comerciales en otros escenarios.

\section{SÍNTESIS}

El proceso de integración andino puede entenderse como un bloque regional que ha vivido no sólo la experiencia de veinte años de la Constitución de 1991, sino que gracias a su creación en 1969 logró ser el puente entre la Constitución de 1886 y la de 1991. Este papel permite, a su vez, determinar cuáles son los cambios trascendentales entre cada una de ellas y cuáles los criterios que permanecen vigentes pese al tránsito constitucional.

El cambio trascendental se manifiesta en la estructura normativa que soportaba a la CAN en la Constitución y la estructura de la Constitución de 1991. Mientras que la de 1886, con la reforma del Acto Legislativo 1 de diciembre 11 de 1968, lo hacía mediante sólo un artículo (76, numeral 18) -causando así varios problemas interpretativos-, la Constitución de 1991 goza de una estructura más completa que permite resolver varios problemas. Así, mientras la CSJ-Sala Plena tuvo que acudir a una interpretación compleja de la Constitución y de la Ley para poder sustentar la vigencia del
Acuerdo de Cartagena -mediante la aplicación de la teoría de acto complejo en actos administrativos y la teoría del tratado marco para poder aplicar el artículo $2^{\circ}$ de la Ley 88 de 1961 -, la Corte Constitucional cuenta con normas expresas que le permiten resolver la vigencia de actos administrativos que dan validez parcial a tratados internacionales -art. 226 de la Constitución de 1991-, el procedimiento internacional en caso de la no aprobación de un tratado internacional -art. 226 ibídem- y las reglas de orientación de las relaciones internacionales -art. $9^{\circ}$ ibídem-. Otro cambio entre la vigencia de la Constitución de 1886 y la de 1991 consistió en el tratamiento que dieron las Cortes en materia de las relaciones entre el ordenamiento del bloque regional y el ordenamiento nacional. Mientras que la CSJ-Sala Plena limitó su jurisprudencia a determinar la existencia o no de un derecho comunitario aplicable en el territorio nacional -teniendo como sentencia de cambio la del 27 de febrero de 1975-, la Corte Constitucional, gracias a tener mayores oportunidades de pronunciamiento, pudo establecer mayores relaciones entre el derecho de la CAN y el colombiano, no sólo en temas de vigencia y efectos, sino otros como la aplicación de los principios de separación de poderes y democrático, la protección de derechos fundamentales y la interacción del bloque regional con terceros.

El punto en común y que une los criterios jurisprudenciales, especialmente a la sentencia de la CSJ-Sala Plena del 27 de febrero de 1975 y a las sentencias de constitucionalidad de la Corte Constitucional C-231 de 1997 y C-227 de 1999, es la identificación de la CAN como un proceso de integración independiente, que no está sujeto a los criterios de un tratado previo -como criterio expuesto en los dos primeros pronunciamientos de la CSJ-Sala Plena- como lo fue el TM -mediante la aplicación del Tratado Marco-. Dicho proceso cuenta con un derecho comunitario autónomo, encargado de regular las relaciones económicas previstas en el AC y en sus protocolos modificato- 
rios, mediante la producción normativa a cargo de instituciones comunitarias dotadas de competencias claras y separadas, normas que gozan de efectos de inmediatez, prevalencia e interpretación y aplicación uniformes.

Sin embargo, pese a que la CAN se entiende como un proceso independiente, la Corte Constitucional no ha establecido un orden de prioridad entre la CAN y las demás negociaciones comerciales de Colombia con otros países. Si bien el artículo 226 legitima a Colombia a internacionalizar sus relaciones comerciales, los artículos $9^{\circ}$ y 227 consagran un tratamiento preferencial a los procesos de integración, especialmente al latinoamericano. No obstante, para la Corte Constitucional dicha consagración no establece, en sí misma, una prioridad de la CAN. Ello ha permitido que Colombia celebre, en varias ocasiones, distintos tratados bilaterales con otros países, ocasionando distintas complicaciones en el interior de la CAN, entre otras, el retiro de Venezuela y la disminución del comercio.

\section{REFERENCIAS}

Acosta R., G., Galfat, G., y Flôres Jr., R. (2006). Comercio e infraestructura en la Comunidad Andina. En Revista de la CEPAL, 90.

Acosta P., J. (2006). La desintegración andina. En revista Foreign Affairs (6) 3 (en español). México.

Armstrong, F. (1975). Political Components and Effects of the Andean Foreign Investment Code. En Standford Law Review, (27), 6.

Arroyave Q., M.A. (2008, enero-junio). Ineficacia crónica del derecho andino: uno de los factores importantes para el ocaso de la Comunidad Andina de Naciones (CAN). En revista Papel Político (13) 1. Colombia.

Barbosa M., D. (1972). El futuro del Grupo Andino. En revista Universitas. Bogotá, Colombia: Univer- sidad Javeriana, Facultad de Derechos y Ciencias Socioeconómicas.

Botero M., R. (1972, enero-diciembre). Pacto Andino y Acuerdo de Cartagena: el diseño de las sentencias. En revista Coyuntura Económica (II) 1. Colombia.

Casas C., A. y Correa, M.E. (2007, julio-diciembre). ¿Qué pasa con la Comunidad Andina de Naciones, CAN? En revista Papel Político (12) 2. Colombia.

Creamer, G. (2004). Regionalismo abierto en la Comunidad Andina: icreación o desviación de comercio? En revista El Trimestre Económico (LXXXI, 1), 281. México.

Fuentes F., A. (2006-07). Situación actual y perspectivas de la Comunidad Andina. En revista Oasis (12). Bogotá, Colombia: Universidad Externado de Colombia.

Fuentes F., A. (2007-08). Contexto histórico y avances de la integración en la Comunidad Andina. En revista Oasis (13). Bogotá, Colombia: Universidad Externado de Colombia.

García de Carvajalino, Y. (1999). La Comunidad Andina. En Revista de Derecho, 12. Barranquilla, Colombia: Universidad del Norte.

Gómez L., D. (1977). Las acciones al portador en la legislación colombiana y el artículo 45 de la Decisión 24 del Grupo Andino. En Boletín de la Superintendencia de Sociedad de Colombia, 21. Recuperado el 5 de marzo de 2011 de http:// www.iadb.org/intal/intalcdi/Derecho_Integracion/ documentos/025-026-Notas_e_Informes_02.pdf

González V., F. (2008). Compatibilidad con la integración en la Comunidad Andina de la negociación de acuerdos de libre comercio con los Estados Unidos por parte de algunos de sus miembros: apuntes preliminares. En revista Agenda Internacional (XV) 26. 
Henao H., J. (1976). Panorama del derecho constitucional colombiano. Colombia: Ed. Temis.

Lamelas C., N., Aguayo L., E. y Cancelo M., M.T. (2005). Integración y crecimiento económico en la Comunidad Andina: más allá de la apertura comercial. En Revista Galega de Economía (14), 1-2.

Milanese, J.P. (2005). Colombia y Venezuela: motores y verdugos de la integración andina. En Cuadernos de CLAEH (28), 91, serie $2^{\circ}$. Montevideo.

Pérez E., J. (1974). El derecho constitucional coIombiano y sus fuentes. Colombia: Ed. Horizontes.

Quindimil L., J. (2006). Instituciones y derecho de la Comunidad Andina. Valencia, España: Universidad de la Coruña, Ed. Tirant Lo Blanch Monografías, 463.

Restrepo P., C. (1995). Constituciones políticas nacionales de Colombia ( $2^{\text {a }}$ ed.). Bogotá, Colombia: Universidad Externado de Colombia.
Saldarriaga B., L.E. (1984). El derecho internacional ante el derecho colombiano: análisis y evaluación de la jurisprudencia de la Corte Suprema de Justicia sobre el control de constitucionalidad de los tratados públicos. Bogotá, Colombia: Universidad Externado de Colombia.

Tremolada A., E. (2006-07). Los pilares jurídicos de la Comunidad Andina: ielementos decisivos para su supervivencia? En revista Oasis, 12. Bogotá, Colombia: Universidad Externado de Colombia.

Vallenas M., H. (2008). Nacimiento y caída del Pacto Andino: teoría y práctica de las teorías de la CEPAL. Recuperado el 20 de marzo de 2011 de http://www.tallerorrego.org/Hugo_Vallenas.html

Vela, B. (2006-07). La encrucijada del proceso andino de integración. En revista Oasis, 12. Bogotá, Colombia: Universidad Externado de Colombia. 